\title{
Technical Translation: A Study of Interference in Three Persian Translations of "Software Engineering”
}

\author{
Ladan Hosseinimanesh \\ English Department, University of Isfahan, Iran \\ Hossein Vahid Dastjerdi \\ Islamic Azad University, Shahreza Branch, Shahreza, Iran
}

\begin{abstract}
The present work is a study of technical translation to examine the negative impact of the source text's lexis and syntax on the target text. In this respect, a technical text - a university textbook - and its three Persian translations were investigated. The focus of the study was on the notion of interference in translation which has been less touched in translation studies. The objective was to specify the ways interference affects comprehensibility. Based on Göpferich (2009), comprehensibility encompasses six dimensions from which the dimension of simplicity was scrutinized in this study. The results showed that most cases of lexical interference were due to choosing wrong or meaningless equivalents. They also showed that the extent of lexical interference was higher than that of syntactic interference. The findings will hopefully have some implications for professional translators and translation students in producing more accurate translations.
\end{abstract}

Index Terms - technical translation, interference, comprehensibility, literal translation, translationese

\section{INTRODUCTION}

Technical translation covers the translation of many kinds of specialized texts in science and technology, and also in other disciplines such as economics and medicine (Williams and Chesterman, 2002). It is believed, as stated by Williams and Chesterman(2002), that the translation of these texts needs a high level of subject knowledge, and a mastery of the relevant terminology. There are other scholars, however, who believe that additional types of mastery are needed for a technical translator (Bédard 1986, Kastberg 2009, Stolze, 2009). Bédard (cited in Hatim and Mason, 1996) explores the myth of technical translation being a matter of one for one exchange of technically precise vocabulary tokens. Hatim and Mason imply that in different areas of translation the common thread is communication (Hatim and Mason, 1996) and for this reason there is similarity between these areas. This means that in their view there exist similarities between literary translation and technical translation. Translating technical texts in the professional environment or in scientific communication is more than handling terminology (Stolze, 2009). Discourse, science, genres and writing techniques are formed in a cultural and historical context. Even at the level of terminology, serious problems exist in technical texts for translation. Both Kastberg (2009) and Stolze (2009) insist that internationally standardized terminology is very much in the minority. For instance, a common technical word such as 'driver' which indicates a computer program enabling the computer to work with a specific additional hardware has got two different

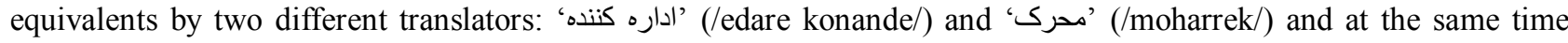
none of them is a good definition for the term. A better translation could be: 'راه 'راه '(/rah andaz/).

In general, like in any other type of translation, a high level of mastery in the source language is also needed. Translation is connected with the problem of understanding the source text. As an example, to support this idea, notice the following: In software engineering: a practitioner's approach, the author talks of concerns about software in near future and uses an idiomatic title: "software: a crisis on the horizon?" The translators' choice is "نزم افزار: بحر انى در افق؟" (/narm afzār buhrāni dar ufugh/) - totally meaningless in Persian. The translators have not understood the English expression "on the horizon" which means "something that is about to happen in near future" and could not decide on an idiomatic equivalent. A possible equivalent is: "نزرم افزار: بحران قريب الوقوع" (/narm afzār: buhrāne gharib ulvoghū’/)

Understanding the source text is the first step in the process of translating and this step could only be taken by mastery in the source language and mastery in the subject domain. Mastery in the subject domain itself is vast and needs checking the cultural context which itself includes the relevant discourse field.

Understanding the source text is the first step in the process of translating and this step could only be taken by mastery in the source language and mastery in the subject domain. Mastery in the subject domain itself is vast and needs checking the cultural context which itself includes the relevant discourse field.

Having studied software engineering, the researchers have faced serious problems regarding textbooks in this field. Textbooks are important sources of information and knowledge for university students. A majority of students in 
computer science are unable to use original textbooks because of lack of knowledge of language. On the other hand, the translations of such books are of low quality and the students cannot make use of them and, therefore, they are only dependent on the knowledge of the instructor of the course. Searching for the reasons, the researchers decided to focus on one of the most important textbooks of software - software engineering: a practitioner's approach (Pressman, 2001)

In the present study the focus is on interference and its influence on the comprehensibility of the text. "Interference refers to the influence of linguistic and other elements of the ST on the TT" (Munday ed., 2009) and is related to the second law of translation proposed by Toury (1995): "the law of interference."

The comprehensibility of translations is assessed by one of the six dimensions Göpferich (2009) has proposed for comprehensibility assessment of a text - simplicity. Simplicity itself is divided into two categories: lexical simplicity and syntactic simplicity.

Research questions

Based on the aforementioned points, the following two research questions were addressed in the present study:

A) In what ways do lexical and syntactic interference result in incomprehensibility in technical translation in terms of simplicity?

B) Which type of interference (lexical or syntactic) is more frequent in the translation of technical texts?

\section{METHOD}

\section{A. Materials}

The materials examined in this study were three available Persian translations of an English university textbook in the field of software engineering titled Software Engineering: a practitioner's approach. The rationale for selecting a computer textbook was the researchers' familiarity with this field, the great importance of this university textbook in computer engineering all over the world, and the difficulty that the students of this field face when using each of the three translations. The Persian translators are: 1) E. Jafarnejad Ghomi and E. Amel Mehrabi (2006), 2) M. M. Salkhordeh Haqiqi (2006) and 3) N. Hashemi Taba (2006).

\section{B. Design}

The study was designed in two phases: 1) identifying instances of interference and 2) assessing comprehensibility.

1.Interference

To identify instances of interference, different definitions and ideas about interference were examined. The intention was to identify cases of negative interference. The following could be relied on as certain indicators of negative (lexical) interference, given that they would result in "unusual patterns" (Newmark, 1991) in TT or they have been done "apparently inappropriately" (Newmark, 1991):

1) Transference

2) Literal translation

3) Calque

a) Lexical calque

b) Structural calque

4) False friends

It has to be emphasized that the above four cases are considered negative interference when they result in: nonnormal or unusual TT patterns indicating the reflection of SL rules and norms or, formal correspondences of linguistic items or structures with different functions in SL and TL, deviations from the code, or deviations from the norm of usage. This applies to both lexical and syntactic cases.

It is worth mentioning that not all the cases of transference (the first and most visible type of interference) are considered negative interference in technical translation. One reason is that in technical writings, there is a need for "precision and clarity" (Aixela, 2009). For example, an expression such as "use-case" in software engineering must be preserved because any translation would distort its clarity.

Syntactic interference, according to Newmark (1991), occurs when:

1) We face totally ungrammatical structures;

2) The SL structure exists but is less common in the target than the source language;

3) The translator neglects the peculiar properties of his or her own language's grammar.

2.Comprehensibility

In her paper (2009), Gopferich presents a communication-oriented framework for the evaluation of pragmatic texts including their translations with regard to their comprehensibility as one if the central factors of their skopos adequacy. In the resulting framework, a distinction is made between six comprehensibility dimensions, 'perceptibility,' 'simplicity,' 'structure,' 'correctness,' 'concision,' and 'motivation.' Requirements derived from the latter four of these dimensions do not only have to be fulfilled by the textual code itself, but also by the mental models to be conveyed by the code. The first two dimensions, 'perceptibility,' and 'simplicity' are related to the textual code itself and not to the mental models. The focus of the present study was only on 'simplicity' - lexical and syntactic - since the 'perceptibility' dimension is to assess extra-textual properties of a text.

\section{Simplicity}


According to Gopferich, the dimension of 'simplicity' or 'linguistic simplicity' refers to the lexis and syntax only. Gopferich offers a framework for assessing a text's simplicity in the form of seeking answers to a number of questions as follows:

For lexical simplicity:

1) Is the lexical item familiar to the target group? (in this case software engineering students)

2) Are unfamiliar specialized terminology explained sufficiently?

3) Is ambiguity avoided?

For grammatical simplicity:

1) Can sentence complexity be reduced?

2) Can nominalizations be transformed into more verbal constructions?

3) Can passive-voice constructions be transformed into active-voice constructions?

4) Can negative sentences be transformed into affirmative ones?

5) Is ambiguity avoided? (pp. 46-48)

Since the simplicity dimension of comprehensibility is related to lexis and syntax only, the present study focused only on lexical and syntactic interference. It is possible to make a relationship between interference and the simplicity dimension of the text in their overlapping area. As mentioned earlier, the study's objective was to assess the effect of interference on comprehensibility (i.e. the textual dimension of comprehensibility called simplicity of a technical text).

\section{Procedure}

In order to check lexical and syntactic interference, 100 sentences and semi-sentences like titles and subtitles and their translations were selected from the original book and the three translations. Although the original book consists of 32 chapters, two of the translations encompass only the first 24 chapters and therefore, the selection range was also from chapters 1 to 24. First, ST sentences were selected without any observation of TTs in order that TT would not affect the selection. Sentences were selected from all the 24 chapters and from different parts of each chapter including the beginning, the end and the middle. It was also tried to pick up sentences from different parts of the text, sentences at the beginning and at the end or in the middle of a paragraph or a part, bulleted or numbered sentences, titles and subtitles, definitions, quotations and examples.

After selecting the sentences, each sentence was searched for lexical and syntactic interference. All instances of interference were listed in tables, together with their type and a short justification on selection. For each translation, two tables were made, one for lexical and another for syntactic interference. For each table, percentage tables were made based on the number of occurrences of each type of interference.

After collecting instances of interference, simplicity questions were answered about each interference case (the above questions). These answers were then presented in tables. At the end, frequencies and percentages were calculated for each table.

\section{DATA ANALYSIS AND RESUlts}

\section{A. Interference}

\section{Lexical interference}

Results for lexical interference in the first translation (Jafar Nejad Ghomi, 2006) are shown in table 1. The translation may be totally "wrong". This means that a term may have different dictionary meanings from which the translator has chosen the wrong one. The reason may be that one equivalent is more common, or the translator has neglected the context which is computer science here. An example for the latter is سازه (/sazeh/) for "construct" which is correct in architectural engineering but not in computer engineering (ساختار (/sakhtar/)). "entity" is another example of this type which is translated as موجوديت (/mojoodiat/) in software engineering not نهاد (/nahad/). "Application" has to be translated as برنامه كاربردى (/barnameh/) برنامه (/barbord/). Another example is "refinement"

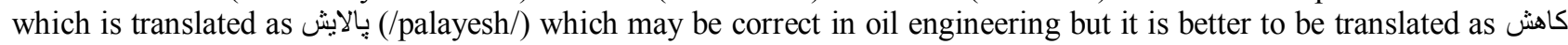
(/kahesh/) in software engineering. In fact a close examination of the original book confirms the second equivalent.

The translation may be "meaningless". This means that: a) the translation is not wrong generally but in its specific co-text or sentence it does not convey any meaning; b) the reader does not know the meaning like some instances of transference accompanied by no extra explanation like "macroscopic" translated as (/makroskopi/).

The translation may be "unnatural". Unnatural here covers those terms or phrases which are uncommon or odd in Persian. For example "automobile business" is translated as تجارت خودروهاى موتورى (/tejarate khodro haye motori/) which is very uncommon in Persian.

Some translations are "not clear". They are not wrong or meaningless but the readers cannot understand them. For instance, "technical kernel" is translated as هسته فنى (/hasteye fanni/) whose meaning is not clear. Some terms like these are better to be translated by a sentence rather that one term.

"Macro element" in not translated correctly because referring to Longman Exams Dictionary states that Macro- (as a prefix) means "large and concerning a whole system rather than particular parts of it". Such a definition brings the

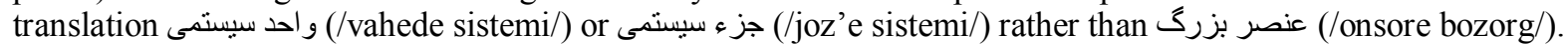


TABLE 1.

FREQUENCIES AND PERCENTAGES OF GHOMI'S LEXICAL INTERFERENCES

\begin{tabular}{|l|l|l|l|l|}
\hline WRONG & MEANINGLESS & UNNATURAL & BETTER TRANSLATION & NONE \\
\hline $31 / 89$ & $28 / 89$ & $10 / 89$ & $13 / 89$ & $7 / 89$ \\
\hline $35 \%$ & $31 \%$ & $11 \%$ & $15 \%$ & $8 \%$ \\
\hline
\end{tabular}

Results for lexical interference in the second translation (Salkhordeh Haghighi, 2006) are shown in table 2 below.

TABLE 2.

FREQUENCIES AND PERCENTAGES OF SALKHORDEH'S LEXICAL INTERFERENCES

\begin{tabular}{|l|l|l|l|l|}
\hline WRONG & MEANINGLESS & UNNATURAL & BETTER TRANSLATION & NONE \\
\hline $31 / 98$ & $22 / 98$ & $10 / 98$ & $22 / 98$ & $13 / 98$ \\
\hline $32 \%$ & $22 \%$ & $10 \%$ & $22 \%$ & $13 \%$ \\
\hline
\end{tabular}

Results for lexical interference in the third translation (Hashemi Taba, 2006) are shown in table 3 below.

TABLE 3.

FREQUENCIES AND PERCENTAGES OF HASHEMI'S LEXICAL INTERFERENCES

\begin{tabular}{|l|l|l|l|l|}
\hline WRONG & MEANINGLESS & UNNATURAL & BETTER TRANSLATION & NONE \\
\hline $33 / 96$ & $28 / 96$ & $5 / 96$ & $19 / 96$ & $11 / 96$ \\
\hline $34 \%$ & $29 \%$ & $5 \%$ & $20 \%$ & $11 \%$ \\
\hline
\end{tabular}

Not all transferences are considered negative interference since in technical prose, sometimes it is necessary to preserve the exact term or phrase for the sake of clarity or unity or in cases where no equivalent exists to replace the

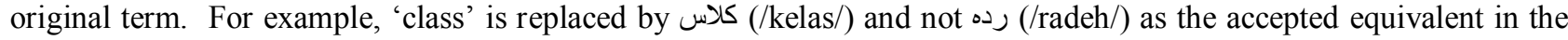
context. This type of transference is preferred to any translation and is not considered as negative. Table 4 below shows some instances of positive transference.

TABLE 4.

INSTANCES OF POSITIVE TRANSFERENCE

\begin{tabular}{|c|c|c|}
\hline Original term & Accepted equivalent & Explanation \\
\hline Calss & " كلاس (transcription) & Technical notion \\
\hline Computer & كامييوتز (transcription) & Technical notion \\
\hline System & سيستم (transcription) & Technical notion \\
\hline ROM & ROM & $\begin{array}{l}\text { Technical notion } \\
\text { A type of memory }\end{array}$ \\
\hline SEI & SEI (بنياد مهندسى نرم افزار) & Important Acronym \\
\hline
\end{tabular}

\section{Syntactic interference}

Syntactic interference of the first translation, Jafar Nejad Ghomi (2006), is presented in table 5 below. Type 3 is related to type 3 of syntactical interference (section 2.2) in which the translator forgets the peculiar properties of his or her own language's grammar.

TABLE 5.

SYNTACTIC INTERFERENCE IN GHOMI'S TRANSLATION

\begin{tabular}{|l|l|l|l|}
\hline & Ungrammatical & Uncommon & Type 3 \\
\hline Frequency & 13 & 13 & 7 \\
\hline Percentage & $41 \%$ & $41 \%$ & $22 \%$ \\
\hline
\end{tabular}

For the second translation, Salkhordeh Haghighi, syntactic interference is shown in table 6 below. For the third translation, Hashemi Taba, syntactic interference is shown in table 7.

TABLE 6.

SYNTACTIC INTERFERENCE IN SALKHORDEH'S TRANSLATION

\begin{tabular}{|l|l|l|l|}
\hline & Ungrammatical & Uncommon & Type 3 \\
\hline Frequency & 7 & 17 & 5 \\
\hline Percentage & $22 \%$ & $53 \%$ & $16 \%$ \\
\hline
\end{tabular}

TABLE 7.

SYNTACTIC INTERFERENCE IN HASHEMI TABA'S TRANSLATION

\begin{tabular}{|l|l|l|l|}
\hline & Ungrammatical & Uncommon & Type 3 \\
\hline Frequency & 8 & 11 & 7 \\
\hline Percentage & $31 \%$ & $42 \%$ & $27 \%$ \\
\hline
\end{tabular}

\section{B. Comprehensibility}

As mentioned before, only one dimension of comprehensibility - simplicity - is under focus in the present study.

Three questions have to be answered for lexical items and five questions have to be answered for syntactic items.

1. Lexical simplicity 
In this part lexical simplicity tables are presented. The cases important to be considered are those which are not familiar to the audience and not explained sufficiently i, e. the answer to the first two questions for them are 'no'. These cases are called "unfamiliar or unexplained" in Table 8 below and Tables 9 and 10. Those cases for which the answer to the third question is 'yes' are called "ambiguous" in the above-mentioned three tables.

TABLE 8.

FREOUENCIES AND PERCENTAGES OF LEXICAL SIMPLICITY CHECK IN GHOMI

\begin{tabular}{|l|l|}
\hline unfamiliar or unexplained & Ambiguous \\
\hline $42 / 90$ & $32 / 90$ \\
\hline $47 \%$ & $35 \%$ \\
\hline
\end{tabular}

TABLE 9.

FREQUENCIES AND PERCENTAGES OF LEXICAL SIMPLICITY CHECK IN SALKHORDEH

\begin{tabular}{|l|l|}
\hline Unfamiliar or unexplained & Ambiguous \\
\hline $57 / 98$ & $29 / 98$ \\
\hline $58 \%$ & $30 \%$ \\
\hline
\end{tabular}

TABLE 10.

FREQUENCIES AND PERCENTAGES OF SIMPLICITY CHECK IN HASHEMI

\begin{tabular}{|l|l|}
\hline Unfamiliar or unexplained & Ambiguous \\
\hline $56 / 96$ & $29 / 96$ \\
\hline $58 \%$ & $30 \%$ \\
\hline
\end{tabular}

\section{Syntactic simplicity}

As mentioned in section 2.2, five questions must be answered in order to identify the extent of simplicity for sentences and syntactical structures. The results are presented in the following tables.

TABLE 11.

FREQUENCY RESULTS FOR SYNTACTIC SIMPLICITY

\begin{tabular}{|l|l|l|l|l|l|l|}
\hline & complexity & Nominal/verbal & Passive/active & Negative/affirmative & ambiguity & total \\
\hline Ghomi & 7 & 10 & 2 & 0 & 5 & 20 \\
\hline Salkhordeh & 9 & 3 & 4 & 0 & 4 & 19 \\
\hline Hashemi & 6 & 5 & 2 & 0 & 3 \\
\hline
\end{tabular}

TABLE 12.

PERCENTAGE RESULTS FOR SYNTACTIC SIMPLICITY

\begin{tabular}{|l|l|l|l|l|l|}
\hline & complexity & Nominal/verbal & Passive/active & Negative/affirmative & ambiguity \\
\hline Ghomi & $22 \%$ & $31 \%$ & $6 \%$ & $0 \%$ & $16 \%$ \\
\hline Salkhordeh & $28 \%$ & $9 \%$ & $19 \%$ & $0 \%$ & $12 \%$ \\
\hline Hashemi & $23 \%$ & $19 \%$ & $8 \%$ & $0 \%$ & $11 \%$ \\
\hline
\end{tabular}

\section{DISCUSSION}

The present study had two major phases. Although the objective was to answer the research questions, each phase had its own importance. The phases were: a) finding instances of interference; b) checking simplicity. A detailed discussion of results and findings of each phase is presented below:

a) Interference

1) Lexical interference

Trying to find lexical instances of interference, the researchers needed justifications on selecting a lexical item as a case of interference. In this regard, it was found that some lexical items were translated in a completely wrong way. But being wrong was not enough to consider the item as interference. The fact that the source of a translation mistake was the influence of the most common dictionary meaning of a term was fascinating in considering it as interference. Such wrong translations show the close relationship between interference and word for word translation. Newmark (1991:82), where discussing interference, points out that "much more often, it is the mark of a bad translator to translate literally, to look at the words without regard to the sense, to remain on the surface of the text." A good example is the word "development". It has been translated "بسط" (") (/bast/) or "/tusa'eh/) in software-related issues and it is used by

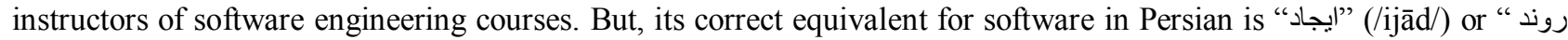
"ايجاد" (/ravande ijād/). The reason is that "development" is commonly translated as "e/) and the translator has not noticed the special context of the word. Longman Dictionary defines the word as follows:

Development:

For new plan/product: the process of working on a new product, plan, idea, etc to make it successful. Example: software development.

In one of the translations, "application" is translated as "كاربرد" (برديرد"kārburd/) where "application" is actually a software program and must be translated as "برنامه كاربردى" (/barnāmeye kārburdi/).

In general, all wrong translations are indictive of translators' negligence of making sense. They have "remained on the surface of the text" (Newmark, 1991:82). 
A distinction between wrong and meaningless is in order here. A slight difference exists between wrong equivalents and meaningless translations. Meaningless translations are those translator-made equivalents which convey no meaning. For example, the term "real-time" is translated as " "زمان حقيقى" (/zamān haghighi/) by using the first dictionary meaning of each of its parts. The question is what does "زمان حقيقى" (/zamān haghighi/) mean in Persian especially when someone is unfamiliar with the source language? The fact is that there is already an equivalent for the term in Persian which is "بلادرنكگ" (/belāderang/). Another example is "prepackaged software components"; the translator translated each word separately and put the translations together: "مؤلفه هاى نرم افزارى بسته بندى شده" (mualefehaye narm afzārie baste bandi

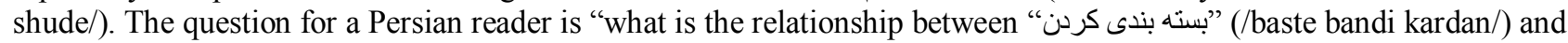

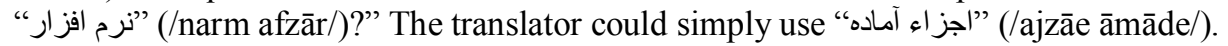

Besides wrong or meaningless equivalents, some translations could be categorized as unnatural. Translating "analysis component" as "مؤلفه تحليل" (/mualefeye tahlil/) shows the influence of the source language phrase on the translator. It is not wrong or meaningless and the reader could infer its meaning, but it is more natural to use an equivalent like " تحليل " تحليل كننده" (/tahlil gar/) or "(tahlil kunande/).

Naturalness or readability of a text is influenced when very long phrases consisting of many words are used in translation. Although natural and flowing in the source language, this may make the translation difficult to understand and may need some adjustments. "Read-only memory" is an accepted term in English; its translation as " حافظه فقط "خواندنى (/hāfezeye faghat khāndani/) is understandable especially for the computer people; yet, there is an easier to read and more accepted equivalent for the term in Persian which is "حافظه دائمى" (/hāfezeye dāemi/). Also, "computer-based

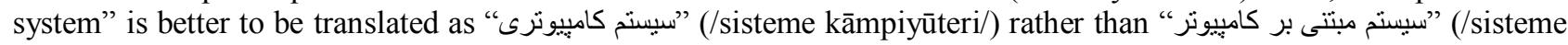
mubtani bar kāmpiyūter/).

It is important to note that making a technical or scientific text easier to read and understand is more helpful for a reader of such texts. Unlike literary translation, in which one might claim that surface structure carries meaning, in scientific or technical translation, the most important point may be to make sense in any way possible. The translator may even need to re-organize the main parts of a technical text if he/she feels this would help his/her reader to better understand.

Some terms and expressions have been translated in a correct, meaningful and even natural way but they still show signs of interference and could have been translated better. Using "نهاد" (/nahād/) as an equivalent for "entity" sounds perfect at the first glance; but "موجوديت" (/mujudiat/) is a better translation in this context.

The above categories were proposed by the researchers based on definitions of interference. They are just for elucidating the point. Still, another important case has been missed so far. It is total transference. Most of the time, transference is the basic type of interference. Examples are: "systematic" as "سيستماتيك" (/sistemātik/), "institute" as "انستينو" (/manstitū/) and "modulār/). At the same time, not all transferences are considered

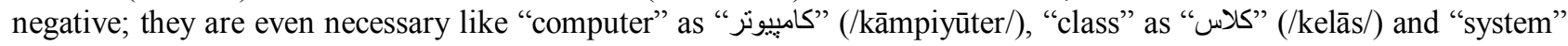
as "سيستر" (/sistem/).

Finally, the researchers could not make any claims about the extent of interference in the data; a standard threshold is needed for one to indicate if interference is high, normal, or low. But it could be concluded that, mistranslations are higher in appearance than bad translations. This is a negative point. It means that accuracy is more in danger than naturalness in the three translations while it occupies higher importance in translation than naturalness.

2) Syntactic interference

Syntactic interference was more difficult to specify than lexical interference. The researchers had to look for unusual syntactic patterns which were a sign of SL norms influence in translation.

In 100 sentences, the total number of recognized lexical and syntactic interference was as follows:

TABLE 13.

THE FREQUENCIES OF LEXICAL AND SYNTACTIC INTERFERENCE IN ALL TRANSLATIONS

\begin{tabular}{|l|l|l|l|}
\hline & Ghomi & Salkhordeh & Hashemi \\
\hline Lexical interference & 89 & 98 & 96 \\
\hline Syntactic interference & 33 & 32 & 27 \\
\hline
\end{tabular}

The second research question - only related to interference - can be answered as follows:

As it is seen in the above table the frequency of syntactic interference in each translation is lower than that of lexical interference.

According to Newmark (1991), "Lexical interference is more dangerous than grammatical interference. Whilst the latter is usually stylistic, lexical interference can distort the meaning of a sentence." Based on Newmark's viewpoint, it could be concluded that it is a weakness for the three translations to suffer from lexical interference more than syntactic interference. This could partially explain why the translations of this special book are misleading in terms of the intended information.

b) Simplicity

1) Lexical simplicity

Regarding simplicity, the first major question to be answered about lexical terms (those suffering from interference in this study) is: "Is the term familiar to the reader? If not, is it explained sufficiently?" It is to be noted that the answers to these questions must have been sought in translations only. The objective was to check the simplicity of the text which 
was to be used by readers. Even if a term had been explained sufficiently in the original text but the explanation was translated literally so that it was not clear enough for TL readers, the answer to the above questions is no.

Based on the above, the researchers checked lexical items one by one to see whether a translation is able to help its readers to understand a term without extra effort (like using other sources). In this respect, the researchers found that a term may be understandable without reference to external sources but that extra effort does exist: the reader had to search for the meaning of a term - refer to different chapters, going forward and backward throughout the book. For such cases as well, the answer was no. Nearly, half of the cases were not explained sufficiently in each translation.

The second question concerning simplicity was: "is ambiguity avoided?" Using the same equivalent for different terms could produce ambiguity. For example, Hashemi translated both the verbs "to develop" and "to extend" as " بسط" دادن" (/bast dādan/). This results in confusion and must be avoided. Translation of both "job" and "task" as " كار "(kār/) is another example.

2) Syntactic simplicity

Syntactic simplicity was checked by answering 5 questions. Two important points could be mentioned here:

- A sentence can be written in a simpler way;

In Salkhordeh and Hashemi most cases suffered from complexity whereas in Ghomi a need to change nominalizations to verbalizations and vice versa (the second case) is seen more than others.

- Passive constructions in many cases are better to be written as active.

The first research question can now be answered:

Comprehensibility is affected by interference in the following ways (they are numbered in order of severity):

Concerning lexical simplicity:

(1)Lexical interference results in terms which are not familiar to the target reader and such unfamiliar items are not explained sufficiently.

Translators' ignorance of meaning implications causes problems for target audience. Incomprehensibility and confusion is the result of translators' sticking to the surface structure;

(2) Lexical interference results in ambiguity. Lexical items may mislead a reader and make him/her infer a meaning which had not been originally intended by the author.

Concerning syntactic simplicity:

(1) Syntactic interference results in unnecessary long and complex sentences and structures which could affect comprehensibility. The reader may have to spend more time and effort to understand a sentence which could otherwise have been written in a simple and straightforward way;

(2) Syntactic interference results in nominalizations that could be written in the form of verbal constructions and sometimes vice versa so that it would be easier for the reader to understand the intended meaning;

(3) Syntactic interference results in ambiguous constructions; constructions which are very shaky in conveying the right meaning to the reader;

(4) Syntactic interference results in passive constructions that are better to be written in active form;

Lexical interference, together with syntactic interference, both denoting word for word translation, could result in unnatural ambiguous constructions which might be difficult to understand and even cause wrong perception. The present study thus aimed at focusing on the specific translation issue that technical translation is not only as difficult as other types like literary translation but also it even demands more attention and expertise.

\section{CONCLUDING REMARKS}

The aim of the present study was to examine closely the translations of an academic technical text. The researchers had to set out with the level of lexis and syntax since they are prelude to further considerations for translation.. For this reason, the focus was laid on interference in translation because this phenomenon has been less touched upon in translation studies. Furthermore, there is a link among interference, word for word translation and surface structure words and grammar. Based on the findings of the study, the following conclusions can be driven:

Although without a threshold in hand one cannot conclude that the level of interference is high or low, the ratio of lexical and syntactic interferences (negative interference) to the amount of data was disappointing. The disappointment becomes worse when one realizes that interference mostly results in choosing wrong equivalents. When the accuracy of translation rather than its naturalness is endangered, the problem of negative interference is serious and must be noticed.

Regarding comprehensibility, interference does influence simplicity - one dimension of comprehensibility pertaining to lexis and syntax. This fact answers the questions "why do translations not satisfy students?" and "why do translations partially occupy an inferior place compared to original texts?" to some extent. The answer is that students do not feel themselves easy in reading and understanding translated texts. In fact, there was not much difference among the three translations regarding interference. This shows that the problem is not limited to one translator. 'Meaning' was in many cases the missing part of the translations under study.

Finally, the translators neglected the target language structure. Following the SL structure, they forgot that a long and complicated sentence could be stated in a very simple form; or a short structure in the SL text may have to be written in a longer form in the TL. They did not notice that the reader must first understand, and second feel himself/herself easy with the text since the book was a technical textbook based on which the student must learn and work. They did not 
notice the preferred equivalents in the context. These are serious weaknesses in translation in general and in translation of technical textbooks in particular.

\section{REFERENCES}

[1] Aixelá, F., \& Javier (2004). The Study of Technical and Scientific Translation: An Examination of Its Historical Development. The Journal of Specialised Translation, 01, 29-47.

[2] Aixelá, F. (2009). An overview of interference in scientific and technical translation. The Journal of Specialised Translation, $11,75-85$

[3] Collins Gem Dictionary of SYNONYMS \& ANTONYMS. (1974). London: Colllins Clear-type press.

[4] Farhang Moaser KIMIA Persian-English Dictionary. (2006). Tehran: Farhang Moaser Publishers.

[5] Farhang Moaser Millennium English-Persian DICTIONARY. (2008). Tehran: Farhang Moaser Publishers.

[6] Göpferich, S. (2009). Comprehensibility assessment using the Karlsruhe Comprehensibility Concept. The Journal of Specialised Translation, 11, 31- 48.

[7] Hatim, B., Mason, I. (1997). The Translator as Communicator. London: Routledge.

[8] House, J. (1997). Translation Quality Assessment: A Model Revisited, Tübingen: Niemeyer.

[9] Kastberg, p. (2009). Cultural Issues Facing the Technical Translator. The Journal of Specialised Translation, 11. Retrieved from http://www.jostrans.org/issue08/art_kastberg.php/

[10] Longman Exams Dictionary. (2006). London: Pearson Education Limmited.

[11] Merriam-Webster's Collegiate Dictionary. (2005). New York: Merriam-Webster.

[12] Montgomery, S. L. (2009). English and Science: realities and issues for translation in the age of an expanding lingua franca. The Journal of Specialised Translation, 11, 6-16.

[13] Munday, J. ed (2009). The Routledge Companion to Translation Studies, London: Routledge.

[14] Neubert, A. (1990). The impact of translation on target language discourse text vs. system. Meta: Translators' Journal, 35, $n^{\circ} 1$, 96-101.

[15] Newmark, P. (1988). A Textbook of Translation. Singapore: Prentice Hall.

[16] Newmark, P. (1991). About Translation. Bristol: Longman Press.

[17] Pressman, R. S. (2001). Software engineering: A practitioner's approach. New York: McGraw-Hill.

[18] Pressman, R. S. (2001). Software engineering: A practitioner's approach. (E. Jafarnejad Ghomi \& E. Amel Mehrabi, Trans.). Tehran: Daneshnegar.

[19] Pressman, R. S. (2001). Software engineering: A practitioner's approach. (M. M. Salkhordeh Haghighi, Trans.). Tehran: Baghani.

[20] Pressman, R. S. (2001). Software engineering: A practitioner's approach. (N. Hashemi Taba, Trans.). Tehran: Gostaresh Olum Paye.

[21] Pym, A. Shlesinger, M. Simeoni, D. ed (2008). Beyond Descriptive Translation Studies. City: John Benjamins.

[22] Stolze, R. (2009). Dealing with cultural elements in technical texts for translation. The Journal of Specialised Translation, 11, 124-142.

[23] Toury, G. (1978). "Interlanguage and its Manifestations in Translation.” Reprinted in 1979 in: Meta 24(2), 223-231. Full text available at http://www.erudit.org/revue/meta/Retrieved on 17 December 2010.

[24] Williams, J., Chesterman, A. (2002). The MAP: A Beginner's Guide to Doing Research in Translation Studies. Manchester: St. Jerome.

Ladan Hosseinimanesh was born in Isfahan, Iran in 1983. She has a BS in software engineering from Sheikh-Bahaie University and an MA in translation studies from the University of Isfahan, Iran. She has worked as a Software Engineer and Programmer and also Translator of specialized (computer) texts for two years. She currently works as an instructor at Sheikh-Bahaie University. She is interested in specialized translation and teaching specialized English. In 2011, she published an article titled "Cultural differences between English and Persian in technical translation" in IJEL (International Journal of English Linguistics).

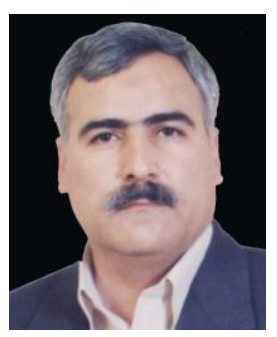

Hossein Vahid Dastjerdi teaches in the English Language Department at the University of Isfahan, Iran. He is associate professor of applied linguistics and has taught courses of variegated character, including translation courses, for years. He has been a fellow of the English Centers at the universities of Isfahan and Shiraz where he has investigated into issues related to materials preparation for GE. and ESP. courses. He is the author of a number of books in this respect. He has also published a good number of articles on discourse, testing and translation in local and international journals.

Dr. Vahid's current research interests include testing, materials development, translation, the metaphoricity of language, discourse analysis, pragmatics and critical discourse analysis. He is presently involved in a number of projects concerning translation studies as well as figurative language use. 